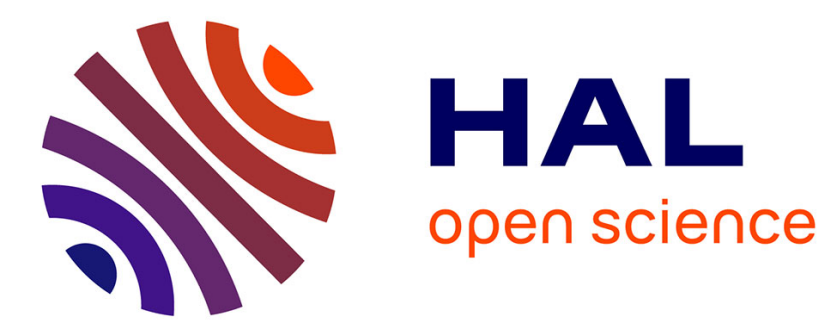

\title{
Postmortem coronary CT angiography
}

Lionel Arrivé, Claire Pichereau, Laurence Monnier-Cholley, Simon Bourcier, Catherine Phan, Eric Maury

\section{To cite this version:}

Lionel Arrivé, Claire Pichereau, Laurence Monnier-Cholley, Simon Bourcier, Catherine Phan, et al.. Postmortem coronary CT angiography. Intensive Care Medicine, 2016, pp.1-2. 10.1007/s00134-0164376-6 . hal-01339414

\section{HAL Id: hal-01339414 https://hal.sorbonne-universite.fr/hal-01339414}

Submitted on 29 Jun 2016

HAL is a multi-disciplinary open access archive for the deposit and dissemination of scientific research documents, whether they are published or not. The documents may come from teaching and research institutions in France or abroad, or from public or private research centers.
L'archive ouverte pluridisciplinaire HAL, est destinée au dépôt et à la diffusion de documents scientifiques de niveau recherche, publiés ou non, émanant des établissements d'enseignement et de recherche français ou étrangers, des laboratoires publics ou privés. 


\section{Postmortem coronary CT angiography}

Lionel Arrivé ${ }^{1}$, Claire Pichereau ${ }^{2}$, Laurence Monnier-Cholley ${ }^{1}$, Simon $_{\text {Bourcier }}{ }^{2}$, Catherine Phan $^{1}$, Eric Maury ${ }^{2}$

${ }^{1}$ Department of Radiology, Saint-Antoine Hospital, Assistance Publique-Hôpitaux de Paris, 184 Rue du Faubourg Saint-Antoine, 75012 Paris, France and Sorbonne Universités, UPMC Université Paris 06, Faculté de Médecine Pierre et Marie Curie

2 Department of Critical Care Medicine, Saint-Antoine Hospital, Assistance PubliqueHôpitaux de Paris, 184 Rue du Faubourg Saint-Antoine, 75012 Paris, France and Sorbonne Universités, UPMC Université Paris 06, Faculté de Médecine Pierre et Marie Curie

Corresponding author:

Lionel Arrivé

Department of Radiology, Saint-Antoine Hospital, Assistance Publique-Hôpitaux de Paris, 184 Rue du Faubourg Saint-Antoine, 75012 Paris

Phone : 33 (1) 49282258

Mail : $\underline{\text { lionel.arrive@ sat.aphp.fr }}$ 
Postmortem coronary CT angiography 
Dear Editor, in the last few decades, medical autopsy rate had markedly decreased owing to several factors such as the family's refusal to provide consent, complexity of a timeconsuming procedure, and fear of litigation in case of missed diagnosis. On the other hand, CT and MR scans increased the accuracy of diagnostic procedures and reduced the need for autopsy. However medical autopsy remains of interest in the case of unexplained sudden death. Recently, postmortem computed tomography (CT) scan emerged as an appealing alternative and compared favourably with conventional autopsy (1). However, because of blood flow cessation, confirmation of diagnosis based on vascular opacification remains difficult. Recent advances in forensic medicine has prompted implementation of new protocols and use of modified heart lung machine, which temporarily restores blood flow and allows diagnosis of vascular pathologies. However, it requires surgical cannulation of the femoral vessels and might be difficult to implement on a routine basis $(2,3)$.

We recently reported the feasibility of postmortem chest CT scan with a contrast medium injection, and chest compression for the diagnosis of pulmonary embolism in 16 intensive care unit (ICU) patients (4). A protocol (approved by our institution's internal review board) was implemented and entailed informing the patient's family of the procedure, keeping the venous catheter after death, and performing the chest CT scan ideally within 60 minutes after death. The procedure was as follows: first, an unenhanced chest CT scan was performed followed by manual injection of a contrast medium $(2 \mathrm{~mL} / \mathrm{kg})$ via the venous catheter. Thereafter, the second chest CT scan was performed after 50 chest compressions to obtain pulmonary artery opacification. Analysis of the left ventricle, aortic arch, and coronary vessels was performed on the third CT scan after another round of 100 chest compressions.

From February 2014 to January 2016, we performed postmortem CT angiography for coronary arteries evaluation, in 28 ICU patients who had died unexpectedly. The mean delay between death and CT was 70 minutes (7-210 minutes). Image quality of coronary CT 
angiography opacification was good in 19 patients (68\%), fair in two patients, and poor in four patients (three of these four patients had extensive coronary calcification) (Fig. 1). In the remaining three patients, coronary opacification was not visualized (one patient had massive postmortem clotting two hours after death; one patient had a large volume of gas in the right ventricle; non opacification was not elucidated in the third patient). Seven cases of coronary occlusion were observed including one stent and one bypass occlusion. In addition, three aortic dissections were demonstrated. However, in our study, we did not observe any postinjection myocardial perfusion defect that could have assisted in a more definite diagnosis of myocardial ischemia as a cause of death (5). Moreover, medical autopsy has never been performed in our patients resulting in significant limitation of our study. In conclusion postmortem coronary CT angiography is an easy-to-perform, minimally invasive technique which obtains a good quality opacification of coronary arteries even in their distal part in most cases.

\section{References}

1) Wichmann D, Obbelode F, Vogel H, et al. Virtual autopsy as an alternative to traditional medical autopsy in the intensive care unit: a prospective cohort study. Ann Intern Med 2012; 156:123-130.

2) Grabherr S, Doenz F, Steger B, et al. Multi-phase post-mortem CT angiography: development of a standardized protocol. Int J Legal Med 2011;125:791-802.

3) Wichmann D, Heinemann A, Weinberg C, et al. Virtual autopsy with multiphase postmortem computed tomographic angiography versus traditional medical autopsy to investigate unexpected deaths of hospitalized patients: a cohort study. Ann Intern Med 2014;160:534-541. 
4) Pichereau C, Maury E, Monnier-Cholley L et al. Post-mortem CT scan with contrast injection and chest compression to diagnose pulmonary embolism. Intensive Care Med 2015;41:167-168.

5) Lee H, Park H, Cha JG, Lee S, Yang K. Myocardial contrast defect associated with thrombotic coronary occlusion. Pre-autopsy diagnosis of a cardiac death with post mortem CT angiography. Korean J Radiol 2015;16:1024-1028. 
Figures legends

Figure 1a: Postmortem CT angiography in a 50 year-old man. Curved MIP reconstruction of right coronary artery only demonstrates small calcified plaques without any stenosis and with positive remodelling. Postmortem CT also demonstrated multiple pulmonary embolisms (not shown) not recognized before postmortem CT angiography.

Figure 1b: Postmortem CT angiography in a 76 year-old man. MIP reconstruction of right coronary artery demonstrates diffuse atherosclerotic changes with multiple stenoses. Occlusion of the mid right coronary artery with several collateral vessels is well shown. Dissection of the ascending aorta is also demonstrated. Extravasation of contrast within pericardium (not shown) was also demonstrated. Ruptured aortic dissection was not diagnosed before postmortem CT angiography. 


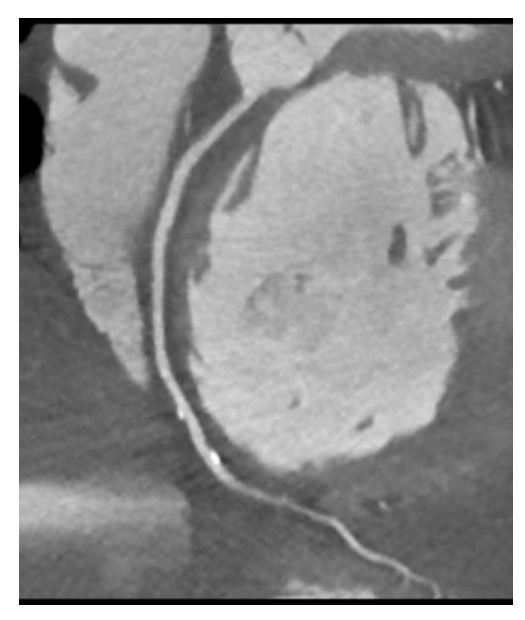

Fig. 1a 


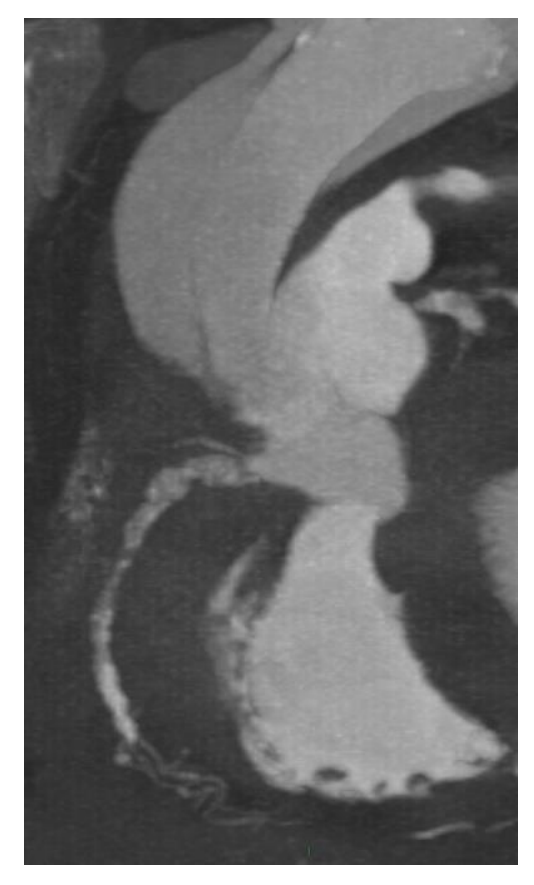

Fig 1b 